\title{
Physics teaching methods: an analysis on peer instruction and modeling instruction
}

\section{Lucas Matheus Araújo Trajano de Souza ${ }^{1}$ e Robert Saraiva Matos ${ }^{2}$}

1 Graduating in Physics. Department of Physics-Federal University of Amapá, Brazil. E-mail: lucasmatheus-baka@hotmail.com 2 Master in Pharmaceutical Sciences. Department of Physics-Federal University of Amapá, Brazil. E-mail: robert_fisic@unifap.br

\begin{abstract}
There is a well known phenomenon related to physics students that concerns the difficulty that these have to understand conceptually what is being taught, since, not infrequently, these show bad results and learning difficulties. Based on this, the present article aim a literature review on different learning methods of physics teaching, among them, two in particular, the Peer Instruction and the Modeling Instruction. While in Peer Instruction the students meet with colleagues and discuss a certain theme among them, in most cases with conceptual testes, the Modeling Instruction is based on the use of interactive whiteboards and exposition of content through the student itself, as well as recommends experiments and other sources of pedagogical support. Many authors advocate that the student, even those with low performance in his classes, can learn better when they work in a interactive way or when they work with their peers. It is starting on this premise that studies in these subjects are based.
\end{abstract}

Keywords: Peer Instruction. Modeling Instruction. Physics Teaching.

\section{INTRODUCTION}

It is easy to observe the difficulties that a student has when he is studying subjects like mathematics, physics, chemistry or biology. Many high school students go through their entire education without understanding conceptually well what they are studying or why they are studying it, and a lot of this happens because of the traditional way of teaching these subjects. Brewe, Kramer and O' Brien. (2009) argue that what differs, in the case of sciences, an expert student from a novice is their capacity to understand conceptually what is being studied. In this way, different teaching methods emerged with the purpose of helping and minimizing these difficulties. Two of them in special, the Modeling Instruction and the Peer Instruction will be analyzed in the present literature review. Dewey (1897), the greatest precursor of the progressive scho- ol, said that the instincts and powers of the student provides material and are the starting point of education, and when the teacher manages to connect with the student's own initiative, teaching becomes easier. We will stress the differences between both methods, among each other, and in relation to the traditional method.

As a starting point, it is important to define what each one represents and what are their main objectives. The Modeling Instruction has a main objective of introducing the student to scientific practices, among them, for example, the creation and development of scientific models, as the name suggests, among others: contact with classmates, self-learning, etc... The usage of whiteboarding and interactive whiteboards is thus particularly important for this model of teaching and, as Blanton (2009) argues, the technology used for this purpose should be seen as pedagogical support, and not the 
other way around.

Peer Instruction, on the other hand, works on the premise that students often learn more from their peers than from their teachers. By organizing the students in groups or in pairs, the method promotes debate and mutual support among them with the aim of improving their performance and their conceptual understanding of the various themes studied. Miller et al. (2014) notes that studies in the field suggest that Peer Instruction is a superior method of teaching, and that this should replace the traditional method. Thus, by applying conceptual tests before and after the discussion with their peers, the method encourages scientific debate among students, thereby making them come to a more correct conceptual definition on the subject.

As it will be evidenced throughout the article, it is important to emphasize that there are differences between these two methods; what are the specific benefits that each one brings to the learning and how they act in the classroom. Thus, the study aims to demonstrate, through a literature review, these aspects and how they were implemented in several physics disciplines, among them, in principal, in the disciplines of Mechanics and Electromagnetism, both in high school courses and in higher education courses.

\section{METHODOLOGY}

Using several articles published in the mentioned areas, the study aims a literature review about those, always stressing the methodologies used by the authors, since all of them use tests or quizzes in classrooms, in direct contact with the students. Both in the study of Modeling Instruction and in Peer Instruction, the authors use questionnaires, either to analyze a student's response time, the way in which he understands physics or the teaching methods that are being applied, what differences they make to their learning as well as to analyze student's self-efficacy. It is worth emphasizing that this is a preliminary study when dealing with the subjects studied and that a more in-depth study is necessary if one wants to better understand the topics addressed. The study of teaching methods is broad and maintains a constancy, so it is always changing, since new things are discovered almost daily.

\section{RESULTS AND DISCUSSION}

\subsection{RECOMMENDATIONS}

According to Turpen and Filkelstein (2009), Erik Mazur is the developer of Peer Instruction. Croch and Mazur (2001) suggest the book Peer Instruction: A User's Manual, written by Erik Mazur and the website "galieo.harvard.edu".

Arizona State University's Modeling Instruction studies are prominent and can be accessed at "modeling.asu.edu" (JACKSON et al., 2008).

\subsection{WHAT IS}

\subsubsection{Modeling instruction}

Using mainly whiteboards for the Modeling Instruction, teachers are continually aiming to create groups and thus assigning to all of them the same task, with a time to be completed. After that time, the groups must form circles and show their results to the entire class, which promotes debate, 
since the results are generally different. The teacher, in this case, always stays out, just giving one tip or another during the presentation (HINRICHS, 2013). Halloun and Hestenes (1986) used the Modeling Instruction to refine the teaching of physics by teaching problem solving in introductory mechanics while focusing in the discussion of the representation of these problems as diagrams, graphs and other mathematical support.

Jackson, Dukerich and Hestenes (2008) describes the Modeling Instruction as a method that emphasizes the construction of conceptual models that centralizes the learning and understanding of science. For them, the method is done in two stages, the first is the creation of the model and the second is the development of this one. The use of interactive whiteboards, where both teacher can change their classes as it is presented, and student can interact with the teacher's classes, is also important (BLANTON, 2008). Hinrichs (2013) stressed that, although there were initial disagreements in debates, students were always able to reach consensus.

Modeling Instruction makes the students more confident by replicating an important activity of scientists that is the model building and discussion, and it promotes in students an engagement with the practices and norms of physics (BREWE et al., 2010). Malone (2008) describes Modeling Instruction as a pedagogy that teaches students to organize their knowledge using basic physics models and data from laboratories by giving different representations to the them.

\subsubsection{Peer instruction}

Peer Instruction is a student-centered teaching method where the teacher has little involvement, serving as an intervener when the student fail to come up with an exact conceptual response. Students are advised to solve conceptual tests and when they receive these, they must solve them alone and then turn to their peers for discussion, and then retake the test $(\mathrm{CROCH}$; MAZUR, 2001). To Croch and Mazur (2001), the greatest differential of Peer Instruction is its ability to adapt to different concepts and educators.

Miller et al. (2014) addresses Peer Instruction by measuring students response time before and after working with peers, noting that response times decreases whenever students talk to peers and that the wrongs answers take longer to be answered, which suggests that students make mistakes because they do not know the answer, rather than finding the wrongs answer to be right. The authors also speaks of a self-efficacy test asking questions about the confidence that the student has in giving the right answers for physics.

By promoting peer-to-peer discussion during the conceptual tests, students are encouraged to discuss with each other during the test, rather than applying it twice; they spend the initial minutes in silence, trying to solve the test themselves, and then ask for peer assistance (TURPEN; FINKELSTEIN, 2009).

Crouch et al. (2007) describes Peer Instruction as an engaging method that makes students go through their disciplines with activities that requires the understanding of the concepts and encourages them to explain those concepts to other students, which makes all of the students in class be more involved since it incorporates a pro- 
cess of questioning more structured and that this process is different from the traditional method, that only engages a few students in the activities.

\subsection{WHAT RESULTS CAN BE EXPECTED FROM THE USE OF THESE METHODS}

Hinrichs (2013), advocates that the Modeling Instruction method is important and that students can learn better interactively. Also holds that, in the method, students can reach consensus on a debate without the help of a teacher. Brewe, Kramer and $\mathrm{O}^{\prime}$ Brien. (2009), shows the view of some students, including James and Katie, who argue that the use of interactive whiteboards in lessons and experiments are two important factors that have made them see physics as something more. The Modeling Instruction aims the debate in classrooms so that the students can reach a conclusion, as well as they can have more freedom, both to discuss and to use the interactive whiteboards (HINRICHS, 2013). The use of the Modeling Instruction for discussion with colleagues has become important in promoting group work (BREWE; KRAMER; O' BRIEN, 2009). Brewe, Kramer and O' Brien. (2009), therefore, shows that the pedagogical support of Modeling Instruction not only serves to introduce a concept of real world in the student, but also serves to their socialization. The organization of knowledge in Modeling Instruction allow the students to show more expert like problem-solving skills as they appear to be more alike the skills of an expert physicist (MALONE, 2008). Halloun and Hestenes (1987), showed that, in introductory physics courses, the Modeling Instruction manages to give a higher achievement and better performance for groups applying it.

After the conceptual tests, the number of wrong answers changed to right answer is greater then the opposite, and, after a semester of Peer Instruction, when students came across traditional teaching again, they showed above-grade performance ( $\mathrm{CROCH}$; MAZUR, 2001). Croch and Mazur (2001) argue that in Peer Instruction it is important for the teacher to apply conceptual testes in accordance with the student's difficulties and knowledge and hence the task of class planning becomes easier as the teacher becomes familiar with the difficulties of his class. In leveled conceptual tests, which are neither too easy nor too difficult, Peer Instruction becomes effective, and most often students change to a right answer after discussing with peers, except those with low self-efficacy; on the other hand, in very difficult tests, self-efficacy is not relevant, and it is up to the teacher to make conceptual tests in steps, so that the student can level up as he solves the various problems (MILLER et al., 2015). It is indispensable to discover the philosophical thought between scientific thought, even in conjecture, since this thought keeps jumping on light supports, always looking for better supports, seeking knowledge (NIETZSCHE, 2013). To Goulart (1987), it would be ideal for teachers to make, through observation of the students, an adaption of their school material in favor of the their intellectual path. With the use of Peer Instruction, students can obtain experience in a variety of scientific practices (TURPEN; FILKESTEIN, 2009). To Turpen and Filkestein (2009), applications of student-centered methods, such as Peer Instruction, are important to the growth and conceptual learning of the student.

Peer Instruction creates a perfect cir- 
cumstance for the teaching of physics and other science subjects. Students engaged with this method shows more easiness in relating abstract ideias and theories with observations, as well as show better performance compared to the students learning with the traditional methods. Peer Instruction is very effective at the construction of scientific knowledge and understanding of science in various situations (HUSSAIN; ANWAR; MAJOKA, 2011). Zhan, Ding and Mazur (2017), shows that Peer Instruction can express more benefits to the students' beliefs and attitudes than the traditional method and that female students benefits, in terms of attitudes, from the method more then male students. Students that works with the same peer during the entire course other than using different peers, as usual in Peer Instructions, seemed to improve their attitudinal views more than the others (ZHAN; DING; MAZUR, 2017). It is important to note that peer instruction is a collaborative method whose principles can be abbreviated as in schema below:

Figure1. Representative scheme for Peer Instruction

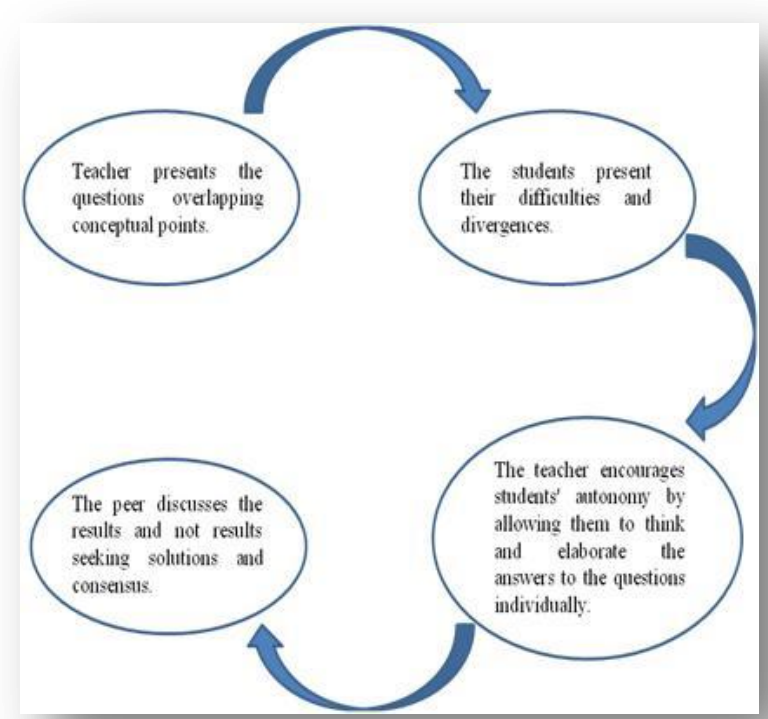

Source: the authors.
3.4 WHAT IS THE RELATIONSHIP THAT THESE METHODS HAVE WITH OTHERS

Brecker (1999), discuss three pedagogical methods and epistemological models, the directive pedagogy, the non-directive pedagogy and the relational pedagogy. He talks about directive pedagogy first, where the student only respond to the teacher, keeping silence and order; a pedagogy where the teacher believes to be the holder of all knowledge and that everything the student learns will be through him, by norm and repetition, doctrine and discipline. He criticizes this method by saying that nothing new happens and that the student becomes tired and discouraged. Then he talks about non-directive pedagogy, where the teacher believes that everything is learned through the student and that he has nothing to do; that he should stay on the side and only encourage the student to think for himself, never teaching, because he does not believes in teaching, he believes that the student already brings knowledge from the crib and that this knowledge should be nurtured. He criticizes this method of teaching by saying that the most needy students do not bring so much knowledge from home, and by not having a teacher's tutoring, he will learn much less than the most favored. Then he talks about the relational method, where the teacher both teaches and learns; where he believes that the student can teach something and that this one has prior knowledge, and that these knowledge's should be stimulated with models, with drawings or anything that incite the student to work with what he already knows in order to learn new things. He says that this teaching method is the most advisable in the eyes of pedagogy, but also that the old pedagogical 
methods do not end with a sociological criticism, although this is important, but with the epistemological criticism; the way in which the teacher approaches the classroom, and that when there are no criticism, the teacher is stuck to such primitive methodologies and common-sense epistemologies that he becomes unable to be aware of what he is doing wrong.

Hestenes (1987) believes that "the mathematical modeling should be the central theme of physics instruction", hence problem solving in physics is a modeling process which constitute a difficult situation since traditionally, when solving a problem, the students only memorize the formulas and manipulate it with substitutions, not caring about the conceptual meaning of it. The ideas of physics are much more than experience and so they can contribute to explain it (BUNGE, 2007).

Blanton (2008), states that with the use of technology, the interaction teacherstudent is romanticized once they meet with this new way to approach teaching. Araújo, Veit and Moreira (2004), observes that by aborting mostly modeling and simulation, models that use of the computer are more concentrated in the Newtonian Mechanics and introductory physics courses and that the development of the instruction must walk hand-in-hand with the teaching research; using technologies without the support of a study on education might be an error. Technology is a pedagogical support and should not be seen in the opposite way, otherwise it is just "an expensive toy" (BLANTON, 2008).

Brewe, Kramer and O' Brien (2009) shows, through the Colorado Learning Attitude About Science Survey (CLASS), a questionnaire with 42 questions, that the attitu- de of physics students improve when faced with Modeling Instruction. Dewey (1897), believed that that social life of the student is the foundation of all his growth and that it gives a unconscious unity of all his efforts, relationships and realizations. The Modeling Instruction has shown to be very effective in expanding the conceptual understanding and problem-solving abilities of the students in contrast with nonmodeling students (MALONE, 2008). Halloun and Hestenes, (1987) advocates that the common sense works to the detriment of scientific thinking in physics courses and that the traditional method can not correct this flaw, showing how important student-centered teaching methods and model-centered approaching are to managing the students beliefs when faced with introductory physics courses.

In the traditional method, the teacher must explain how to solve each calculation and each problem and say when it is right or wrong. This method contradicts a thesis of psychology that consists in giving a main role to the activity of the student in the construction of his own knowledge (GOULART, 1987). The traditional method can only show good results in advanced physics courses where the students are already aware of the scientific thinking and the way that the teachers give their classes; for introductory physics courses, the Modeling Instruction show better results since the students don't yet know how scientific thinking works and hence they need to analyze and work with their own perceptions in order to the common sense give place to scientific beliefs (HALLOUN; HESTENES, 1987). Teachers who have implemented Modeling Instruction are no longer traditionally viewed as something to be feared and are now 
seen as instructors or coaches, always encouraging students to understand physics by their own efforts (JACKSON; DUKERICH; HESTENES, 2008). Jackson, Dukerich and Hestenes (2008) holds that the student upon entering high school sees Newtonian mechanics only with his concept of the worId that was previously founded, a concept that is usually wrong, and that traditional teaching can not change that conception into the correct one. The Modeling Instruction, in turn, can circumvent this failure, making the student visualize for himself, in practice, what is the correct concept and why the previous one was wrong. Kant (2009) says that the criticism of reason leads to science and that dogma in reason, without criticism, causes unsubstantiated statements that lead to more unsubstantiated statements, following up skepticism.

In Peer Instruction, self-confident students take less time to answer questions, even if they are answered wrongly, while students with little confidence take longer. Self-confidence is a key factor in building a student's knowledge (MILLER et al., 2014). Miller et al. (2015) suggests that interventions should be made to increase students' self-efficacy, either with modeling experience or social encounters to address the ability of students to succeed in their studies, or to reduce stress by not applying tests beyond the ability of the class, among others. All ethics begins when you take into account that each person is infinitely important (NIETZSHE, 2013). When a teacher fails to teach the students a given subject, they struggle to learn it alone with inferior alternatives in order to deal with their difficulties and they are left to unravel important knowledge's by observing the performance of professors and assistants and struggling with practice problems (HESTENES, 1987).

Bonamino et al. (2010) says that literacy, whether in reading or in science, is connected to the knowledge and skills that students need to have in order to function effectively in society, being acquired throughout life, even after school, and interacting with peers, with colleagues and with community are considered fundamental for the improvement of their literacy. Each teacher has his or her particlar application of Peer Instruction and students receive several benefits during Peer Instruction, as well as demonstrate better results as compared to the traditional instruction (TURPEN; FINKELSTEIN, 2009).

Brewe et al. (2010), advocates that in introductory physics, students were learning with the traditional teacher-centered method and passive students, and that this method isolate them as well as encourages competition and do not focus on conceptual learning. Modeling Instruction is an inclusive teaching method that can be supportive for all students, including those that are historically under-represented and that reformed instruction, a practice that encourages collaboration other than competition, is an important way of creating an inclusive learning environment (BREWE et al., 2010). Goulart (1987) states that in the behaviorist model, learning must be observed from the responses that students give. Thus, the teacher has the role of making sure, when manipulating the conditions of the student's environment, that the student is learning, and the student has the role of learning and accomplishing goals, which are evaluated according to his behavioral changes.

The Just-in-Time teaching is a web-based assignment response system where the students submit their answer before the 
class so the teachers can learn, see the difficulties of the student and "tailor the classroom sections" just-in-time. Studentstudent interaction, student-faculty interaction and time on task are important factors to the successfulness of Just-in-Time teaching (PATTERSON, 2005). Sambataro (2000) says that Just-in-Time teaching does not replace classrooms instruction and that IT lends to just-in-time learning. Just-inTime teaching is a useful tool for Peer Instruction by helping choose the appropriate concept test to class according to the students' difficulties (LEMOS; ROCHA; MENEZES, 2016). Zhan, Ding and Mazur (2017), shows that students using Peer Instruction seem to show better attitudinal shifts when compared to the students using the traditional method and that while in the traditional method, students tend to have a more novicelike attitudes, in Peer Instructing they showed more expertlike attitudes. Novicelike beliefs being described as seeing physics knowledge as disconnect facts, which is different from the expertlike beliefs that is the belief that physics is a coherent topic that uses reason to solve problems and questions.

\section{CONCLUSION}

The application of different teaching methods is important in the construction of student's learning. Modeling Instruction has a number of attributes, including the opportunity for students to feel like real scientists and to be able to debate with groups, teachers, and colleagues. By being encouraged to study for themselves, students learn to deal not only with current disciplines but also with the later ones. Peer Instruction also promotes this kind of relationship, as it also encourages them to study for themselfs before and after school, as well as stimulates discussion and conversation among the class. As shown in the papers analyzed here, the two teaching methods showed a great influence on the improvement of student performance and on their conceptual understanding of what is being studied, thus being important implementations in classrooms.

\section{BIBLIOGRAPHY}

ARAUJO, I.; VEIT, E.; MOREIRA, M. Uma revisão da literatura sobre estudos relativos a tecnologias computacionais no ensino de Física. Universidade Federal do Rio Grande do Sul, jan. 2004.

BECKER, F. Modelos pedagógicos e modelos epistemológicos. Educação e Realidade, v. 19, n. 1, p. 89-96, 1999.

BLANTON, P. Using interactive whiteboard to enhance student learning. The Physics Teacher, v. 46, n. 3, p. 188-189, mar. 2008. BONAMINO, A.; ALVES, F.; FRANCO, C.; CAZELLI, S. Os efeitos das diferentes formas de capital no desempenho escolar: um estudo à luz de Bourdieu e Coleman. Revista Brasileira de Educação, v. 15, n. 45, sept./dec. 2010.

BREWE, E.; KRAMER, L.; O' BRIEN, G. Modeling instruction: positive attitudinal shifts in introdutory physics measured with CLASS. The American Physical Society, v. 5, n. 1, june 2009.

BREWE, E. et al. Toward equity through participation in Modeling Instruction in introductory university physics. The American Physical Society, v. 6, may 2010.

BUNGE, M. Física e filosofia. São Paulo: Perspectiva, 2007.

$\mathrm{CROUCH}, \mathrm{C}$. et al. Peer instruction: engaging 
students one-on-one, all at once. ResearchBased Reform of University Physics, v. 1, n. 1, apr. 2007.

$\mathrm{CROUCH}, \mathrm{C}$.; MAZUR, E. Peer instruction: ten years of experience and results. American Association of Physics Teachers, vol. 69, v. 9, p. 970-978, sept. 2001.

DEWEY, J. My pedagogic creed. School Journal, v. 54, p. 77-80, jan. 1897.

GOULART, I. Psicologia da Educação: fundamentos teóricos e aplicações à prática pedagógica. Rio de Janeiro: Editora Vozes Ltda., 1987.

HALLOUN, I.; HESTENES, D. Modeling instruction in mechanics. The American Journal of Physics, v. 55, n. 5, p. 455-462, jan. 1987.

HESTENES, D. Toward a modeling theory of physics instruction. The American Journal of Physics, v. 55, n. 5, p. 440-454, may. 1987.

HINRICHS, B. E. Sharp initial disagreements then consensus in a student led whole-class discussion. Physics Education Research Conference 2013. Portland. p. 181-184, 2013.

HUSSAIN, S.; ANWAR, S.; MAJOKA, M. Effect of peer group activity-base learning in students' academic achievement in physics at secondary level. International Journal of Academic Reasearch, v. 3, n. 1, jan. 2011. JACKSON, J.; DUKERICH, L.; HESTENES, D. Modeling instruction: an effective model for science education. Science Educator, v. 17, n. 1, p. 10-18, 2008.

KANT, I. Crítica da Razão Pura. São Paulo: Martin Claret, 2009.

LEMOS, W.; ROCHA, H.; MENEZES, C. Adoption of just-tine-time teaching, peer instruction and problem-baseed learning - impacts on engineering students performance. International Journal on Active Learning, v. 1, n. 1, p. 89-98, july/dec. 2016.

MALONE, K. Correlations among knowledge structures, force concept inventory, and problem-solving behaviors. The American Journal of Physics, v. 4, nov. 2008.

MILLER, K. et al. Conceptual question response times in peer instruction classrooms. The American Physical Society, v. 10, aug. 2014.

MILLER, K. et al. Response switching and self-efficacy in peet instruction classrooms. The American Physical Society, v. 11, feb. 2015.

NIETZSCHE, F. O Livro do Filósofo. São Paulo: Escala, 2013.

PATTERSON, E. Just-in-Time teaching: technology transforming learning -2 a status report. United States Air Force Academy. Colorado Springs. 2005.

SAMBATARO, M. Just-in-Time Learning. ComputerWorld, april 2000.

TURPEN, C.; FINKELSTEIN, N. Not all interactive engagement is the same: variations in physics professors' implementation of peer instruction. The American Physical Society, v. 5, aug. 2009.

ZHANG, P.; DING, L.; MAZUR, E. Peer instruction in introductory physics: a method to bring about positive changes in students' attitudes and beliefs. The American Physical Society, v. 13, n. 1, june 2017.

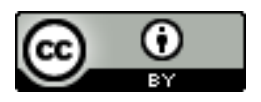
access article distributed under the terms of the Creative Commons Attribution License, which permits unrestricted use, distribution, and reproduction in any medium, provided the original work is properly cited.

Article received on March 11, 2017.

Evaluated November 24, 2017.

Accepted on December 12, 2017.

Published on December 19, 2017. 
How cite this article (ABNT):

SOUZA, Lucas Matheus Araújo Trajano de; MATOS, Robert Saraiva. Physics teaching methods: an analysis on peer instruction and modeling instruction. Estação Científica (UNIFAP), Macapá, v. 7, n. 3, p. 51-60, set./dez. 2017. 